\title{
Study on the Wearing Performance of Compression Stockings and Its Influence on the Blood Flow Velocity of Lower Limbs
}

\author{
Hainan Liu ${ }^{1}$, Ling Cheng ${ }^{2, *}$ \\ ${ }^{1}$ School of Textile Science and Engineering, Tiangong University, 399 Binshui West Road, Tianjin, China \\ ${ }^{2}$ School of Physical Science and Technology, Tiangong University, 399 Binshui West Road, Tianjin, China
}

\begin{abstract}
Compression stockings can reduce venous pressure and improve venous return by applying progressive pressure on the lower limbs from bottom to top, thereby preventing and treating venous diseases of the lower limbs. The purpose of this research is to conduct a preliminary understanding and analysis of compression stockings through various mechanical properties and feel styles of compression stockings, and to explore the effect of compression stockings on the blood flow of lower limbs by using blood flow speed as an experimental index. The results show that low-grade compression stockings are more effective in accelerating blood flow in healthy people under sedentary conditions.
\end{abstract}

\section{Introduction}

Chronic lower extremity venous disease is a common vascular disease and frequently-occurring disease. Its incidence increases with age. The incidence of women is higher than that of men. Chronic venous disease is a syndrome of a series of symptoms caused by poor venous blood return and high venous pressure due to abnormal structure or function of the vein[1-2]. Venous diseases account for about $60 \%$ of vascular surgical diseases and often occur in the lower extremities. Compared with medication and surgery, compression therapy is a scientific, simple and effective treatment method[3]. Studies have shown that compression therapy can increase the action of the calf muscle pump to reduce venous pressure and improve venous return. Appropriate compression can reduce the diameter of the main vein, thereby increasing blood flow velocity[4].

Compression stockings, a medical textile that can promote venous blood return to the heart and relieve symptoms related to venous diseases of the lower extremities, have been proven to be an effective non-surgical treatment[5-6]. This pressure difference can speed up the blood flow, reduce or drive away the stagnation of venous blood at the distal end of the limb, and protect the venous valve to achieve the effect of prevention and treatment[7].

Scientific pressure levels and gradient distribution are the key to the medical performance of compression stockings, but the progressive pressure it presents is the result of the comprehensive effect of various mechanical properties of the fabric. Studies have shown that the production parameters of compression stockings have a significant impact on their pressure characteristics. Similarly, the wearing and medical performance of compression stockings are the comprehensive results of various mechanical properties of the fabric[8-9]. Therefore, the purpose of this study is to get a preliminary understanding of compression stockings from the perspective of evaluating fabric styles and analyzing the mechanical properties of materials, and use ultrasonic Doppler blood flow detectors to monitor the skin blood flow changes of healthy adults wearing different grades of compression stockings.

\section{Materials and methods}

\subsection{The basic characteristics of compression stockings}

This study tested and analyzed 3 grades of elastic compression stockings produced in Taiwan. According to the manufacturer's statement, their compression socks have passed the ISO 9002 quality system certification. Compression stockings exert the greatest pressure on the ankle and show a gradually decreasing pressure distribution up the leg. Therefore, the compression stockings of each grade are divided into three parts for analysis, as shown in Figure 1, and marked a, b and c respectively from top to bottom. Combined with the basic structure test of the sample, the basic characteristics of the tested sample are shown in Table $\mathbf{1}$.

*chengling@tiangong.edu.cn 


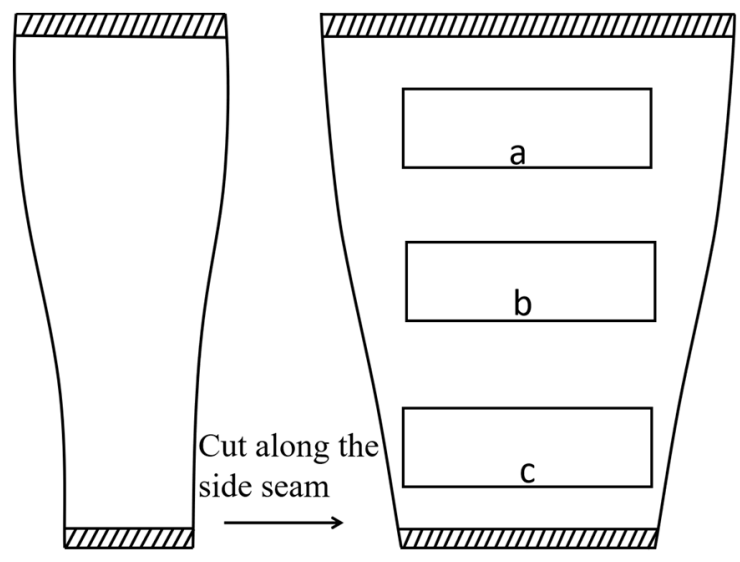

Figure 1. Schematic diagram of compression stockings sampling.

Table 1. The basic parameters of the sample.

\begin{tabular}{|c|c|c|c|c|c|c|}
\hline \multicolumn{2}{|c|}{ Pressure rating } & $\begin{array}{l}\text { Thickness } \\
\text { (cm) }\end{array}$ & $\begin{array}{l}\text { Weight } \\
\text { (g) }\end{array}$ & $\begin{array}{c}\text { Transverse } \\
\text { density } \\
\text { (row } / 5 \mathrm{~cm} \text { ) }\end{array}$ & $\begin{array}{c}\text { Longitudinal } \\
\text { density } \\
\text { (row } / 5 \mathrm{~cm} \text { ) }\end{array}$ & $\begin{array}{l}\text { Recommended medical } \\
\text { functions }\end{array}$ \\
\hline \multirow{3}{*}{ Light } & $\mathrm{a}$ & 0.706 & 1.41 & 59 & 119 & \multirow{9}{*}{$\begin{array}{l}\text { Prevent varicose vein } \\
\text { and thrombosis, reduce } \\
\text { heavy and fatigue. } \\
\text { For the treatment of mild } \\
\text { varicose veins, pain, } \\
\text { swelling. } \\
\text { For the treatment of } \\
\text { severe varicose veins, } \\
\text { severe edema, leg ulcers, } \\
\text { lymphedema. }\end{array}$} \\
\hline & $\mathrm{b}$ & 0.707 & 1.45 & 72 & 116 & \\
\hline & $\mathrm{c}$ & 0.712 & 1.54 & 88 & 111 & \\
\hline \multirow{3}{*}{ Moderate } & $\mathrm{a}$ & 0.705 & 1.44 & 60 & 110 & \\
\hline & $\mathrm{b}$ & 0.720 & 1.41 & 76 & 106 & \\
\hline & $\mathrm{c}$ & 0.736 & 1.43 & 94 & 101 & \\
\hline \multirow{3}{*}{ Strong } & $\mathrm{a}$ & 0.735 & 1.55 & 58 & 110 & \\
\hline & b & 0.738 & 1.60 & 72 & 107 & \\
\hline & $\mathrm{c}$ & 0.744 & 1.62 & 89 & 103 & \\
\hline
\end{tabular}

\subsection{Assessment of material performance}

\subsubsection{INSTRON-3300 Fabric universal strength} machin. This instrument can be used to test textile materials, rubber and other materials for tensile, compression, tearing and other experiments. The latest technology is used in measurement, control, recording, etc., and an automatic control and data processing system is formed with a microprocessor as the core. It has the advantages of high measurement accuracy, wide measurement range, stable clamping force, and no damage to the sample.

\subsubsection{PhabrOmeter Fabric feel evaluation system.}

The feel style of fabric is one of the important quality attributes of textile products, which affects the wear performance and comfort of clothing. PhabrOmeter fabric evaluation system is a new kind of measuring instrument system developed by American Xinsaibao Technology Company for fabric sensory performance evaluation. It can realize the fast, objective and high-throughput testing of multiple indicators of fabric handle style. A single test can obtain multiple indexes such as softness, smoothness, rigidity, drape, and wrinkle recovery at the same time.
2.2.3 Skin blood flow velocity measurement. The experimental equipment is a portable ultrasound Doppler blood flow detector, which has the advantage of non-invasive and continuous measurement of skin blood flow velocity. The device probe emits a certain frequency of ultrasound, and it will reflect when it encounters the red blood cells moving in the blood vessel. The movement speed of the red blood cells can be obtained by the frequency difference between the incident wave and the reflected wave, which is the blood flow speed.

\section{Experimental protocol}

The whole process of the test is carried out in a laboratory with an ambient temperature of $(23 \pm 2){ }^{\circ} \mathrm{C}$ and a relative humidity of $(65 \% \pm 2 \%)$. Before testing, all fabric samples were allowed to stand for 24 hours in the aforementioned standard laboratory to minimize the instability of the knitted fabric.

\subsection{Tensile performance test}

To test the tensile properties of fabrics, most of them need to test the breaking strength of the fabric, that is, the maximum load when the sample is stretched and broken at a certain tensile speed. The sample for this test is compression stockings. In daily life, the fabric can rarely 
be pulled to fracture, testing its breaking strength is of little help to this experiment, so this test uses the constant elongation method Stretch the sample and analyze the stress-strain curve when the sample is stretched to the corresponding elongation. When wearing compression stockings, transverse stretching is produced in order to adapt to the shape of human legs, and the longitudinal deformation is small. Therefore, the deformation of pressure socks can be viewed approximately as a simplified problem of lateral stretching. In this study, only transverse stretching is carried out on fabrics to test the transverse tensile properties of fabrics, and the test indicators are shown in Table 2.

In the experiment, the sample was selected to be stretched to $15 \mathrm{~cm}$ in one direction and the stretching rate was $100 \mathrm{~mm} / \mathrm{min}$. The tested sample size is $5 \mathrm{~cm} 15 \mathrm{~cm}$, and the effective size is $5 \mathrm{~cm} 10 \mathrm{~cm}$.

Table 2. Tensile property test index.

\begin{tabular}{|c|c|}
\hline Test index & Index introduction \\
\hline Initial modulus & $\begin{array}{l}\text { The initial modulus is used to describe the difficulty of the knitted fabric to } \\
\text { deform under a small external force, and it is also one of the indicators that } \\
\text { characterize the elasticity of the knitted fabric. The size of the initial modulus } \\
\text { indicates how easy it is for the fiber to deform under a small load. }\end{array}$ \\
\hline Elastic recovery rate & $\begin{array}{l}\text { Elastic deformation refers to the recoverable deformation of the fabric after the } \\
\text { external force is removed. For knitted fabrics, it is expressed by the tensile } \\
\text { elastic recovery rate. }\end{array}$ \\
\hline Plastic deformation rate & $\begin{array}{l}\text { Plastic deformation refers to the deformation that the fabric cannot recover after } \\
\text { the external force is removed under the specified conditions. It is expressed by } \\
\text { the plastic deformation rate. }\end{array}$ \\
\hline
\end{tabular}

\subsection{Evaluation of fabric handle style}

In the evaluation of fabric handle style, the tested sample is a circle with a radius of $10 \mathrm{~cm}$, and the test indexes are shown in Table 3.

Table 3. Test index of fabric hand style.

\begin{tabular}{cl}
\hline Test index & \multicolumn{1}{c}{ Index introduction } \\
\hline Stiffness & $\begin{array}{l}\text { Stiffness is related to fabric flexibility. The higher the stiffness value is, the } \\
\text { more crisp the fabric is. } \\
\text { The compression resistance of fabric is related to its softness. Low compression } \\
\text { resistance can be considered as high softness. The higher the softness value is, } \\
\text { the softer the fabric is. } \\
\text { Softness } \\
\text { Surface friction is a kind of surface resistance due to sliding. The greater the } \\
\text { smoothness value, the smoother the fabric surface. } \\
\text { The smaller the drape index is, the better the drape of the fabric is. } \\
\text { The fabric was measured twice (with an interval of } 5 \text { minutes). The difference } \\
\text { between the two test values is the index value of wrinkle recovery ability of the } \\
\text { fabric. The higher the wrinkle recovery rate is, the better the wrinkle recovery } \\
\text { performance is. } \\
\text { Describe the elasticity of the fabric. The higher the elastic index is, the better } \\
\text { the elasticity of the fabric is. }\end{array}$ \\
Stretch Index &
\end{tabular}

\subsection{Blood flow velocity of skin was measured}

The blood flow measurement experiment requires that the subjects do not exercise vigorously within 24 hours before the experiment, and do not eat spicy or alcohol-containing irritating food within 17 hours. After entering the laboratory, the subjects had a quiet rest for 30 minutes, so that they could adapt their mental and physical conditions to the current environment. Since the blood flow changes of the human body are affected by many minor factors, even if the same person is in different environment and mood, the blood flow changes are also different every day, so the test time is selected as 13:30-18:30 every day to ensure the accuracy of the experiment.

Immobilisation, and prolonged standing and sitting have been suggested to be the principal aetiological factors in the pathogenesis of such venous disorders.
Therefore, a point above the knee in the sitting position is selected as the test point, and no pressure contact is guaranteed during the test.

\section{Results and Discussion}

\subsection{Test results and analysis of tensile properties}

It can be seen from Figure 2(a) that as the pressure level increases, the initial modulus value increases; the same level, the initial modulus value of the fabric at different positions from top to bottom is also increasing. Which indicates that the higher the pressure class is, the greater the pressure value is, the more difficult it is for the pressure socks to deform under the action of less external forces. 
From Figure $2(\mathbf{b}, \mathbf{c})$, it can be seen that as the pressure level increases, the elastic recovery rate decreases while the plastic deformation rate increases. That is to say, the elastic recovery rate of the fabric has a negative correlation with the clothing pressure. In other words, the better the elasticity of the compression stocking under the same elongation condition is, the lower the clothing pressure in this part is. This is because a knitted fabric with good elastic recovery requires less recovery force, and the pressure perpendicular to the surface of the human body is less, and the corresponding clothing pressure is also less. From the perspective of pressure comfort of tight-fitting knitted garments, under

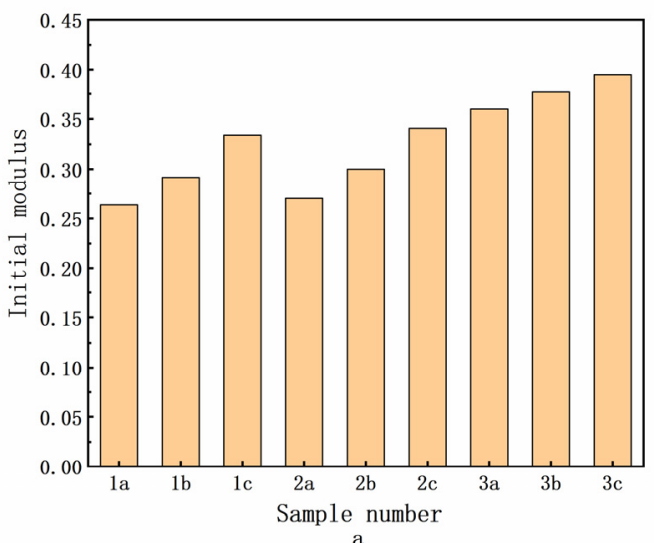

the same clothing allowance, garments made of knitted fabrics with good elasticity not only fit tightly, but also do not restrict the movement of the human body, and have better sports comfort. On the other hand, in the same grade of compression stockings, the elastic recovery rate of the sample position from top to bottom is increasing, and the plastic deformation rate is decreasing. It is known that the greater the elastic recovery rate of the knitted fabric is, the smaller the plastic deformation rate is, and the better its elasticity is. It indicates that the closer the sample position is to the ankle, the better its elasticity is.

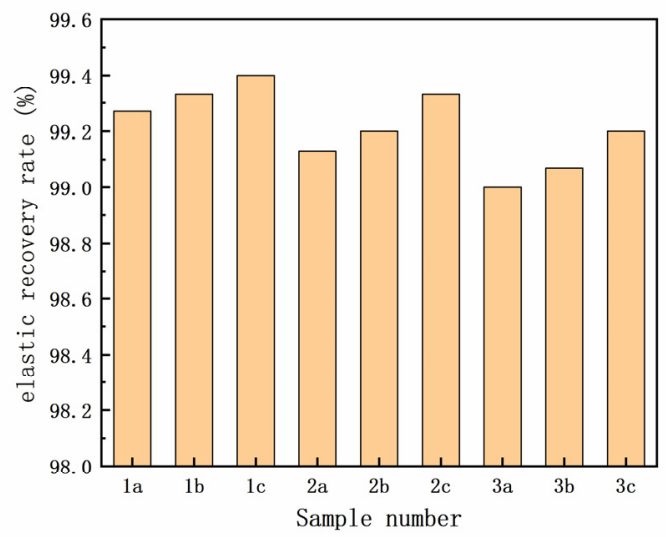

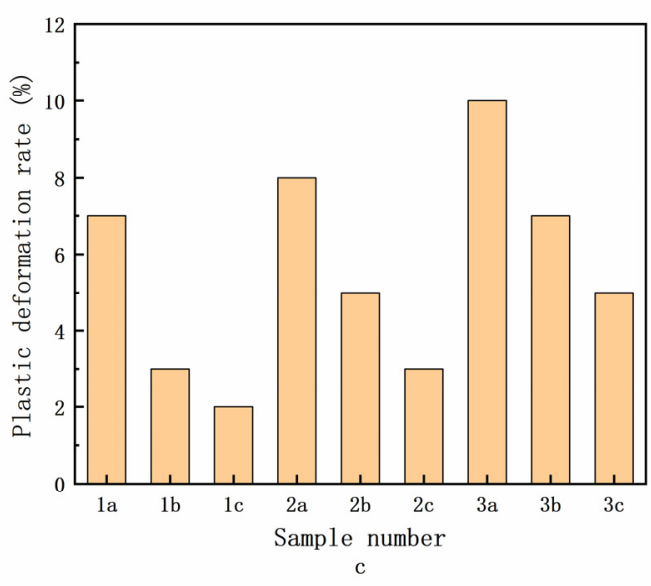

Figure 2. Histogram of tensile performance indicators

\subsubsection{Correlation analysis between sample} parameters and performance indexes. Correlation analysis is to study whether there is a certain dependence relationship between phenomena, and to explore the related direction and degree of correlation between specific dependent phenomena. It is a statistical method to study the correlation between random variables. The correlation coefficient is a measure of the closeness of the relationship between two or more variables. The correlation coefficient calculated based on the sample data is called the sample correlation coefficient and is denoted as $r$. The value of the correlation coefficient $r$ is between -1 and 1 , but can be any value within this range. $0.8<|\mathrm{r}|<1$ is high correlation, $0.5<|\mathrm{r}|<0.8$ is moderate correlation, $0.3<|\mathrm{r}|<0.5$ is low correlation, and $|\mathrm{r}|<0.3$ can be regarded as irrelevant. In the case of positive correlation, the two variables change in the same direction; in the case of negative correlation, the two variables change in the opposite direction.

The spss software is used to analyze the correlation between the structural parameters of the sample and the tensile performance test indicators. The analysis results are shown in Table 4. 
Table 4. Correlation between structural parameters and performance indexes.

\begin{tabular}{|c|c|c|c|c|c|c|c|}
\hline & & $\begin{array}{l}\text { initial } \\
\text { modulus }\end{array}$ & correlation & $\begin{array}{l}\text { elastic } \\
\text { recovery } \\
\text { rate }\end{array}$ & correlation & $\begin{array}{l}\text { Plastic } \\
\text { deformation } \\
\text { rate }\end{array}$ & correlation \\
\hline \multirow{4}{*}{$\begin{array}{l}\text { Pearson } \\
\text { correlation } \\
\text { coefficient }\end{array}$} & Weight & 0.923 & $\begin{array}{l}\text { Highly } \\
\text { positive } \\
\text { correlation }\end{array}$ & -0.365 & $\begin{array}{l}\text { Low } \\
\text { negative } \\
\text { correlation }\end{array}$ & 0.135 & irrelevant \\
\hline & Thickness & 0.848 & $\begin{array}{l}\text { Highly } \\
\text { positive } \\
\text { correlation }\end{array}$ & -0.412 & $\begin{array}{l}\text { Low } \\
\text { negative } \\
\text { correlation }\end{array}$ & 0.13 & irrelevant \\
\hline & $\begin{array}{l}\text { Transverse } \\
\text { density }\end{array}$ & 0.358 & $\begin{array}{l}\text { Low positive } \\
\text { correlation }\end{array}$ & 0.588 & $\begin{array}{l}\text { Moderate } \\
\text { positive } \\
\text { correlation }\end{array}$ & -0.807 & $\begin{array}{l}\text { Highly } \\
\text { negative } \\
\text { correlation }\end{array}$ \\
\hline & $\begin{array}{l}\text { Longitudin- } \\
\text { al density }\end{array}$ & -0.483 & $\begin{array}{l}\text { Low negative } \\
\text { correlation }\end{array}$ & 0.153 & irrelevant & 0.154 & irrelevant \\
\hline
\end{tabular}

It can be seen from Table 4 that the correlation between the thickness and grammage of the sample and the initial modulus is positive and the correlation is strong, that is, the thickness and grammage have a significant effect on the initial modulus of the fabric. The transverse density of the sample had a moderate positive correlation with the elastic recovery rate of the fabric and a high negative correlation with the plastic deformation rate of the fabric, that is, increasing the transverse density of the fabric appropriately would increase its elastic property.

\subsubsection{Linear regression analysis of stretch rate and} load. Linear regression refers to a method of establishing a linear regression model for objects with correlations, and inferring another unknown quantity through a known quantity. As shown in Figure 3, the elongation and the corresponding load value of the 9 samples are distributed around a straight line, and the regression function between the two sets of data is considered to be a linear function. Using Spss software to curve fitting the relationship between the tensile rate of the sample and the tensile load, Table 5 can be obtained.
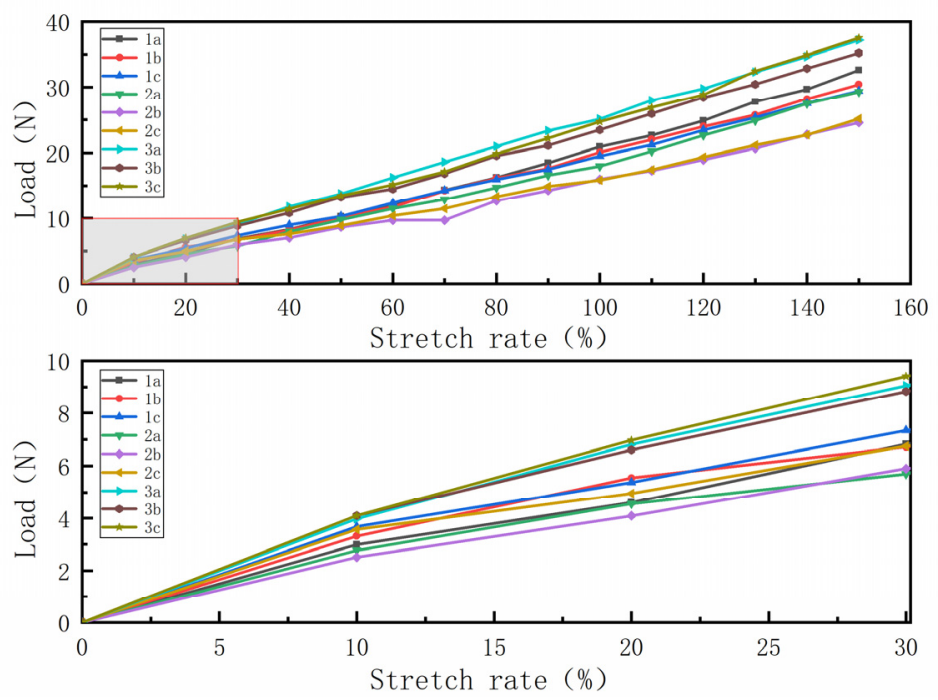

Figure 3. Sample tensile curve.

Table 5. Fitting equation of specimen tensile curve.

\begin{tabular}{ccc}
\hline The sample number & Regression equation & Correlation coefficient \\
\hline 1a & $\mathrm{y}=0.21 \mathrm{x}+0.009$ & 0.997 \\
1b & $\mathrm{y}=0.194 \mathrm{x}+0.656$ & 0.997 \\
1c & $\mathrm{y}=0.186 \mathrm{x}+1.19$ & 0.997 \\
2a & $\mathrm{y}=0.188 \mathrm{x}+0.178$ & 0.996 \\
2b & $\mathrm{y}=0.155 \mathrm{x}+0.515$ & 0.994
\end{tabular}




$\begin{array}{lll}2 c & y=0.153 x+1.275 & 0.992 \\ 3 a & y=0.238 x+1.636 & 0.998 \\ 3 b & y=0.224 x+1.474 & 0.997 \\ 3 c & y=0.236 x+1.339 & 0.996\end{array}$

The correlation coefficients of the curve fitting equations are all above 0.99 , and the fitting effect is good, so the linear equation can be used to fit the stretching curve equation. The extensibility of fabric can be expressed by the tensile force under a certain elongation rate. The lower the tensile force under the same elongation rate is, the better the extensibility of fabric is. It can be known from the curve fitting equation of the sample that the tensile elasticity of the tested sample is very well, and a small load can produce a large elongation.

Figure 4 is the linear fitting equation diagram corresponding to three samples in different grades of compression stockings. It can be seen that when the sample at different positions has the same elongation, the required load value has little difference, especially at the two positions b and c. Among the three grades, sample a requires the largest load when large elongation occurs, that is, the compression stocking has the worst extensibility near the knee.
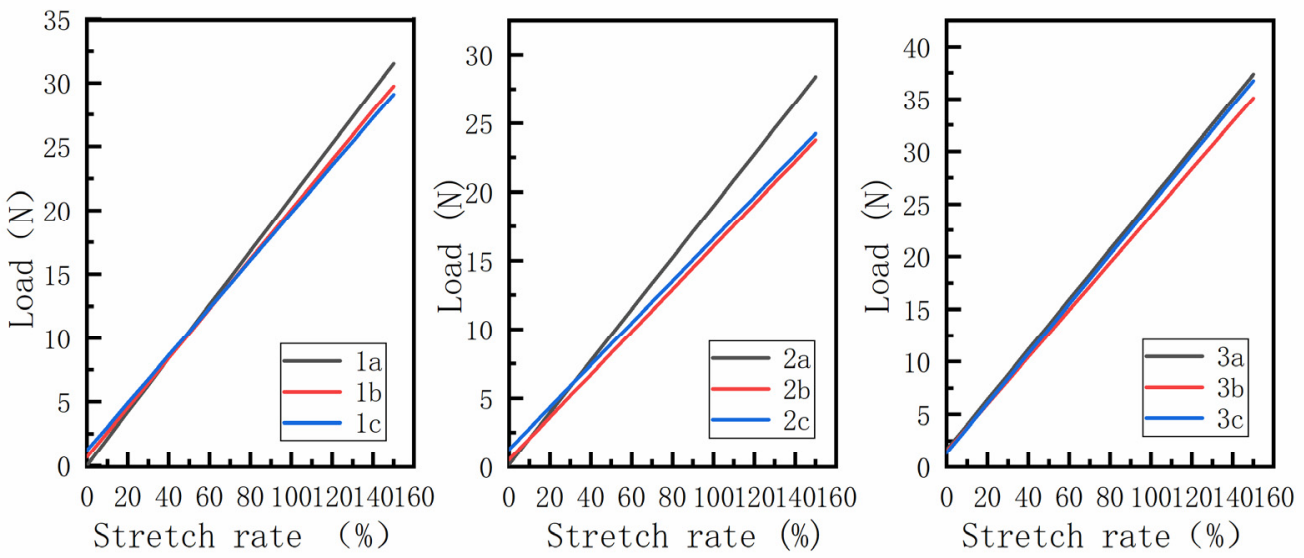

Figure 4. Linear fitting equation of stretch of socks with different grades of pressure.

Figure 5 is the linear fitting equation diagram of samples with the same position but corresponding to different grades. When the same elongation occurs, the maximum load is required for the three-stage pressure socks, and this is true regardless of whether the elongation is small or large. But for the first-stage and second-stage compression stockings, the required load value is not much different when the elongation is small; and when the greater elongation occurs, the load value required for the first-stage is significantly greater than the load value required for the second-stage. This may be caused by other properties of the fabric.
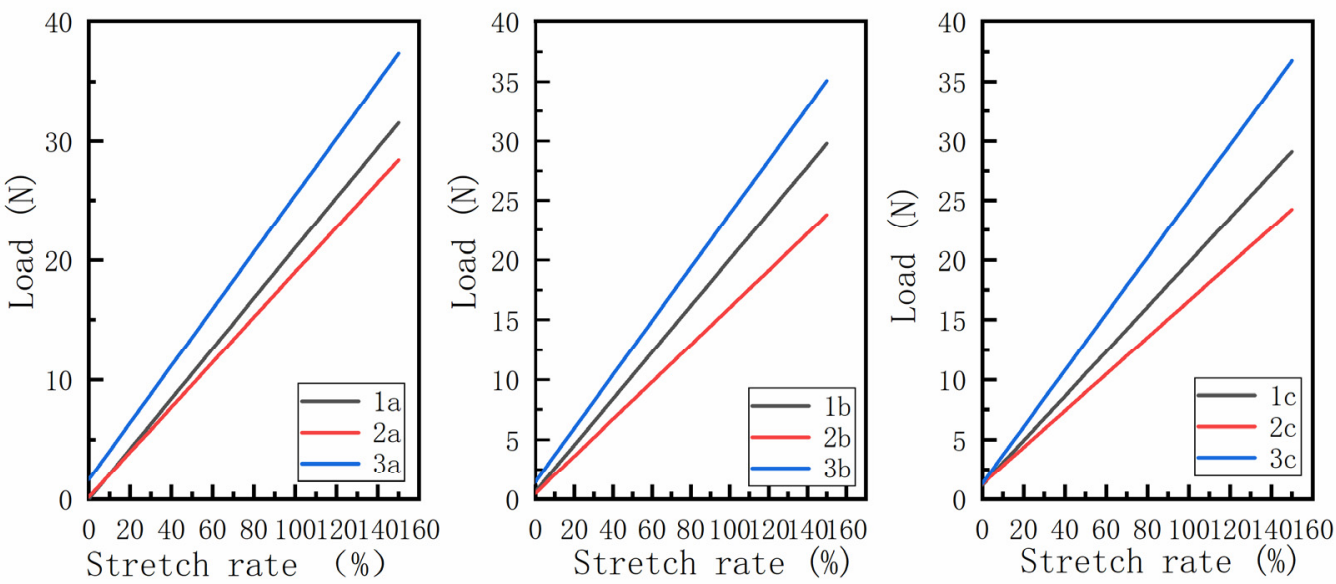

Figure 5. Drawing of linear fitting equation for different samples. 


\subsection{The result and analysis of fabric hand feeling style evaluation}

The PhabrOmeter fabric feel evaluation system can simulate human hand touching the fabric and give sensory performance evaluation. Through the data, an objective understanding of the style characteristics and feel performance of compression stockings can be realized.
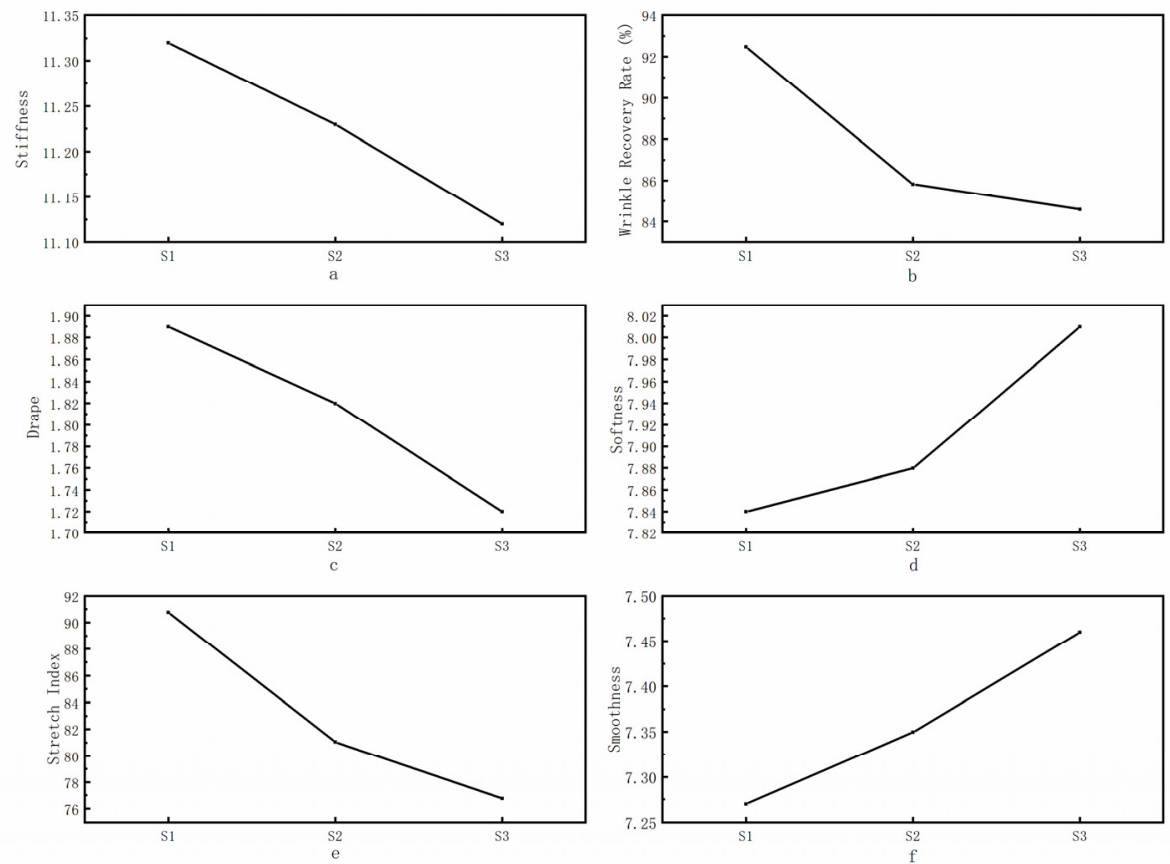

Figure 6. Hand feel style index.

Generally speaking, the different style indexes of three grades of pressure socks have little difference. The higher the pressure level is, the greater the softness index and smoothness index are. The higher the softness is, the softer the cloth body is, and the higher the smoothness is, the smoother the surface of the fabric is, and the lower the friction force is. If the pressure level is too high, the stronger the restraint to the legs, the wearing comfort will be lower than that of the pressure socks with weak pressure level. Therefore, reducing the friction on the legs and improving the softness of the socks will improve the wearing comfort of high-grade pressure socks. On the other hand, the lower the pressure level is, the weaker the leg restraint is. It can be seen from Figure 6 (e) that the drape coefficient of low-grade pressure socks is higher, which indicates that the effect of close fitting is not as good as that of high-grade pressure socks. In daily wearing, in order to ensure the accurate pressure value and gradient distribution of pressure socks, it is necessary to consider the fitness and shape retention of pressure socks. The stiffness, elasticity index and wrinkle recovery rate of low-grade pressure socks are higher than those of high-grade pressure socks. The higher the stiffness and wrinkle recovery are, the better the bending resistance of the fabric is, and the higher the elastic index is, the better the elasticity and relaxation resistance of the fabric are. On the whole, it can improve the weak binding and pressure attenuation.

\subsection{Test results and analysis of skin blood flow velocity}

When the compression stockings were not worn, the blood flow velocity of the subjects did not fluctuate much. An independent sample $t$ test was performed on the blood flow speed when wearing different grades of compression stockings and when not wearing it, and it was concluded that the blood flow speed in each group of data was significantly different from the blood flow speed in the unbound state $(\mathrm{p}<0.01)$. 


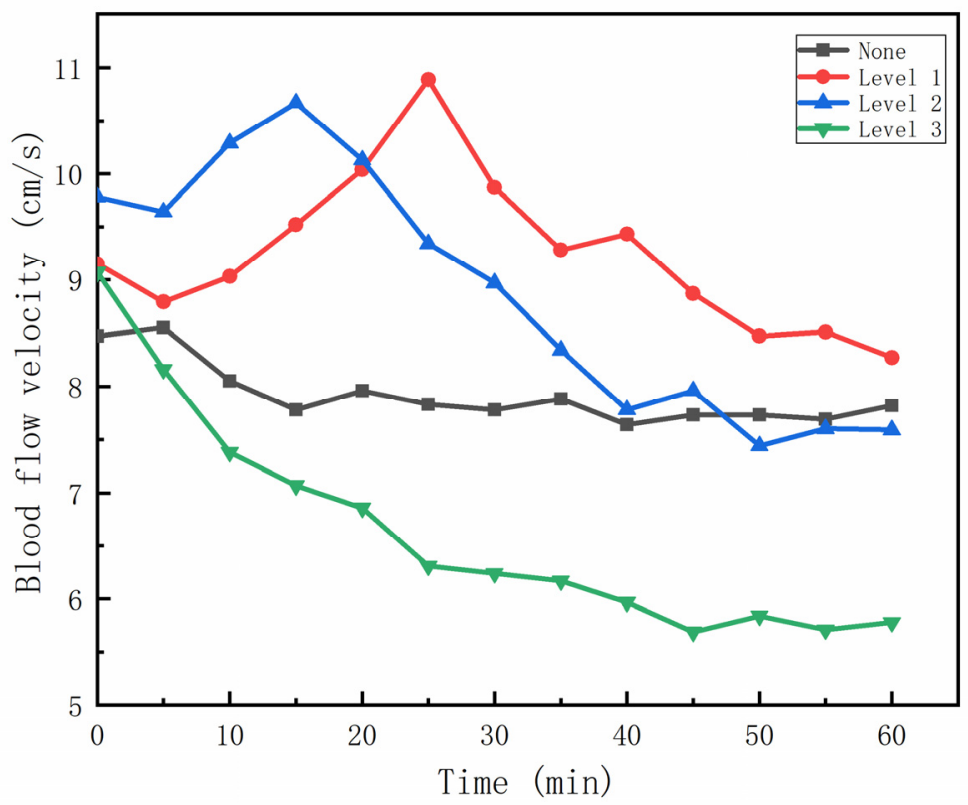

Figure 7. Diagram of blood flow velocity under different pressure states.

It can be seen from the figure that the primary and secondary pressure stockings can accelerate the blood flow speed in a period of time after wearing. But the difference is that the blood flow velocity of grade I pressure socks reaches the peak value after wearing them for about 25 minutes, which is $37 \%$ faster than that when they are not wearing. After that, the blood flow velocity began to slow down gradually in the remaining 35 minutes, but it was always higher than that when the pressure socks were not worn. On the other hand, the blood flow velocity of the secondary pressure socks reached the peak after 15 minutes of wearing, which was $35 \%$ faster than that without wearing. Then the blood flow velocity began to slow down gradually in the remaining 45 minutes, and the blood flow velocity value was slightly lower than that without pressure socks after wearing 45 minutes.

Compared with the first level compression stockings, the peak blood flow velocity of the two is almost the same. At the same time, the average blood flow velocity within the first 20 minutes of the second level compression stockings is significantly greater than that of the first level. This not only reflects the promoting effect of pressure on blood flow velocity, but also within a certain period of time, the greater the pressure value is, the greater the blood flow velocity is.

Compared with the second-level compression stockings, the third-level promotion of blood flow is only reflected in the instantaneous state just after wearing it. Within 60 minutes of the test, the blood flow rate has been in a state of decline. This means that excessive pressure can inhibit the blood flow rate of normal people.

4.3.1Correlation analysis. From the previous section, it can be seen that the pressure grade and wearing time of pressure socks have certain influence on blood flow velocity of lower limbs. Therefore, the correlation analysis of blood flow velocity, pressure level and time is made, as shown in Table 6.

Table 6. Correlation analysis table.

\begin{tabular}{ccccc}
\hline & & Blood flow & Pressure rating & Time \\
\hline \multirow{3}{*}{ Pearson correlation } & Blood flow & 1.000 & $-.413^{* *}$ & $-.450^{* *}$ \\
& Pressure rating & $-.413^{* *}$ & 1.000 & .054 \\
& Time & $-.450^{* *}$ & .054 & 1.000 \\
Sig. (bilateral) & Blood flow & & .002 & .001 \\
& Pressure rating & .002 & & .702 \\
& Time & .001 & .702 & 52 \\
& Blood flow & 52 & 52 & 52 \\
& Pressure rating & 52 & 52 & 52 \\
\hline
\end{tabular}

According to the results of table correlation analysis, the correlation coefficient between blood flow velocity and pressure grade is -0.413 , and the correlation coefficient between blood flow velocity and wearing time is -0.45 , and the significance level is less than 0.01 . Therefore, the correlation between blood flow velocity and pressure grade and wearing time is negative and strong.

\section{Conclusion}

This study mainly evaluated the wearing performance of compression stockings and their effect on human lower limbs from the perspective of fabric performance and physiology. In terms of pressure rating and mechanical properties, studies have shown that the structural 
parameters, tensile properties and overall effects of fabrics are closely related to the pressure rating of compression socks. For example, as the pressure level increases, the heavier the fabric is, the greater the initial modulus of the fabric is, that is, the stronger the fabric's resistance to low stress deformation.

It is known that the decrease in the venous blood flow velocity of the lower extremities is generally considered to be one of the main reasons for the formation of venous diseases of the lower extremities[10].Therefore, blood flow velocity can be an effective response to venous function. In this study, blood flow velocity was measured in healthy women, and it was found that there was little fluctuation in blood flow velocity without pressure. On the other hand, within 1 hour of wearing different grades of compression stockings, the first-level and second-level compression stockings increased the blood flow speed by $37 \%$ and $35 \%$, respectively, while the third-level compression stockings had an inhibitory effect on the blood flow rate. The results show that compression stockings with lower pressure levels are more suitable for people who are sedentary in daily life, while those with higher pressure may be more suitable for people with severe venous diseases of the lower extremities.

The limitation of this study is that the subjects were female subjects with healthy vein function and leg shape, and blood flow velocity was not studied in patients with various degrees of venous diseases. Therefore, in order to make compression stockings play a greater role in the prevention and treatment of venous diseases, further research is still needed to investigate the effect of high-grade compression stockings on lower extremity venous diseases.

\section{References}

1.Hamdan and Allen 2012 Jama. 308(24) 2612-21.

2.Born D P, Sperlich B, Holmberg H C 2013 Int J Sport Physiol. 8(1) 4-18.

3.Fu W, Liu Y and Fang Y 2013 Int J Adv Robot Syst. 10(1) 66-.

4.W Blättler and Zimmet S E 2008 Phlebology. 23(5) 203-205.

5.Partsch H 2005 Dermatol Surg. 31:625-630.

6.Liu R, Kwok YL, Li Y, Lao TT, Zhang X and Dai XQ 2005 Dermatol Surg. 31:615-624.

7.Mosti G and Partsch H 2011 Eur J Vasc Endovasc Surg. 42 261-6.

8.Burak S 2016 J Ind Tex. 47(6) 1083-1096.

9.Liu R, Kwok Y L, Li Y, et al 2010 J Appl Polym Sci. 104(1) 601-610.

10.Sigel B, Edelstein AL, Felix RF and Memhardt CR 1973 Arch Surg. 106 38-43. 